\title{
Saúde mental, direito e psicologia no Judiciário: interlocuções na Seção Psicossocial da Vara de Execuções Penais do Tribunal de Justiça do Distrito Federal e Territórios
}

Mental health, law and psychology in the judiciary: dialogues in the Psychosocial Section of the Criminal Executions Court of the Federal District Court of Justice

\section{Érica Quinaglia Silva}

Antropóloga e professora adjunta da Universidade de Brasília. Brasília, Brasil.

\section{Mônica Oliveira da Cruz}

Estudante de graduação em Saúde Coletiva na Universidade de Brasília. Brasília, Brasil.

\section{Rayssa de Paula Dantas Trajano}

Estudante de graduação em Terapia Ocupacional na Universidade de Brasília. Brasília, Brasil.

Resumo: A Seção Psicossocial da Vara de Execuções Penais do Tribunal de Justiça do Distrito Federal e Territórios ocupa-se do atendimento a pessoas que cumprem medida de segurança, ou seja, uma sentença judicial que as define como doentes e criminosas. Este trabalho visa entender os caminhos percorridos por essas pessoas, quais sejam a internação e o tratamento ambulatorial, e verificar como têm se configurado as interlocuções entre saúde mental, direito e psicologia no judiciário.

Palavras-chave: saúde mental, direito, psicologia, medida de segurança.

Keywords: mental health, law, psychology, security measures.

\section{Introdução}

As pessoas atendidas na Seção Psicossocial da Vara de Execuções Penais do Tribunal de Justiça do Distrito Federal e Territórios cumprem medida de segurança, ou seja, uma sentença judicial que as define não somente como criminosas, mas também como doentes. Perigosas e loucas, essas pessoas são consideradas inimputáveis e/ou semiimputáveis. De acordo com o artigo 26 do Código Penal (Decreto-Lei oㅜ 2.848, de 7 de dezembro de 1940), inimputável é "o agente que, por doença mental ou desenvolvimento mental incompleto ou retardado, era, ao tempo da ação ou da omissão, inteiramente incapaz de entender o caráter ilícito do fato ou de determinar-se de acordo com esse entendimento". 
Essa pessoa fica isenta de pena. Ainda segundo o Código Penal, semi-imputável é "o agente [que], em virtude de perturbação de saúde mental ou por desenvolvimento mental incompleto ou retardado, não era inteiramente capaz de entender o caráter ilícito do fato ou de determinar-se de acordo com esse entendimento". Essa pessoa pode ter sua sanção reduzida de um a dois terços.

Encaminhadas ao contexto judiciário, no âmbito da medida de segurança, há dois caminhos a serem percorridos por elas: o tratamento ambulatorial e a internação em hospital de custódia, que, no Distrito Federal, ocorre na Ala de Tratamento Psiquiátrico, localizada na Penitenciária Feminina do Gama.

Nesses percursos, essas pessoas são submetidas a exames, pareceres psiquiátricos e psicológicos, geralmente anuais, cujo objetivo é verificar a cessação de periculosidade. Juntamente com esses exames, requisitos, como tempo de reclusão e existência de parente que acolha essas pessoas, são observados para permitir uma decisão judicial favorável à desinternação condicional, ou seja, a uma desvinculação da justiça. Trata-se de um terceiro caminho possível. ${ }^{1}$

Este trabalho tem como objetivo entender as trajetórias percorridas por pessoas consideradas inimputáveis e/ou semi-imputáveis que cumprem medida de segurança. Verificar quantas pessoas estão nesta condição e como tem sido conduzida essa decisão judicial é fundamental para entender e aprimorar a interlocução entre o direito e a psicologia na Seção Psicossocial da Vara de Execuções Penais do Tribunal de Justiça do Distrito Federal e Territórios.

\section{Objetivos}

Esta pesquisa visa entender os caminhos percorridos por pessoas que cumprem medida de segurança, quais sejam a internação e o tratamento ambulatorial, e verificar como têm se configurado as interlocuções entre saúde mental, direito e psicologia no judiciário.

Como objetivos secundários, intenta-se atualizar os dados levantados pelo Censo realizado em 2011 sobre $A$ custódia e o tratamento psiquiátrico no Brasil especificamente no Distrito Federal. Ademais, como forma de aprofundar e alargar todo o arcabouço documentado, o trabalho visa realizar uma pesquisa qualitativa com os profissionais da

\footnotetext{
${ }^{1}$ As informações referentes ao funcionamento da Seção Psicossocial da Vara de Execuções Penais do Tribunal de Justiça do Distrito Federal e Territórios foram retiradas de BRANDI, Caroline Quinaglia A. C. S. A fala dos inimputáveis: uma investigação clínica sobre verbos pathicos no contexto da medida de segurança. Dissertação de Mestrado em Psicologia apresentada ao Programa de Pós-Graduação em Psicologia Clínica e Cultura da Universidade de Brasília. Brasília, 2012.
} 
Seção Psicossocial da Vara de Execuções Penais do Tribunal de Justiça do Distrito Federal e Territórios, a dizer 3 psicólogas, 2 assistentes sociais e 1 pedagoga.

\section{Metodologia}

Em uma primeira etapa, serão analisados todos os prontuários ativos das pessoas inimputáveis e/ou semi-imputáveis que cumprem medida de segurança na Seção Psicossocial da Vara de Execuções Penais do Tribunal de Justiça do Distrito Federal e Territórios. Para a verificação de possíveis lacunas nos dados fornecidos pelos prontuários, recorrer-se-á aos processos judiciais.

É importante ressaltar que, nesses casos, a Constituição brasileira, em seu artigo 5º, incisos XXXIII e XXXIV, e artigo 93, inciso IX, bem como o Código Civil, no artigo 155, asseguram que todos os julgamentos e atos processuais dos órgãos do poder judiciário devem ser públicos, ressalvados os casos de processos que correm em segredo de justiça. Tal entendimento é reforçado, ainda, pela Lei no 11.111, de 5 de maio de 2005.

Na segunda etapa, serão realizadas entrevistas semiestruturadas com os profissionais da Seção Psicossocial da Vara de Execuções Penais do Tribunal de Justiça do Distrito Federal e Territórios para verificar como é feito o acompanhamento das pessoas que cumprem medida de segurança e analisar a relação entre psicologia e direito no contexto judiciário.

Assim, trata-se, em um primeiro momento, de um projeto de pesquisa documental feita mediante análise de prontuários e processos públicos e, em um segundo momento, de um projeto de pesquisa qualitativa por meio de entrevistas com os profissionais que trabalham com atenção psicossocial. Para que sejam garantidos o anonimato, o sigilo e a confidencialidade dos dados dos sujeitos envolvidos, o plano de trabalho foi revisado e aprovado quanto aos seus aspectos éticos pelo Comitê de Ética em Pesquisa do Instituto de Ciências Humanas (CEP/IH) da Universidade de Brasília (UnB).

Como estratégias de proteção aos dados dos sujeitos, serão adotados, ainda, os seguintes procedimentos: 1 . assinatura, por parte da equipe de pesquisa, de um termo de responsabilidade pelo uso de informações e cópias de documentos para fins de pesquisa; 2. a pesquisa documental dos prontuários e processos será realizada nas dependências do TJDFT, o que garantirá o sigilo e a confidencialidade dos dados; 3. quanto à pesquisa qualitativa, ela será conduzida mediante a assinatura de um Termo de Consentimento Livre e Esclarecido para a coleta de dados em profundidade.

A pesquisa não acarretará dano, risco ou constrangimento aos sentenciados e suas famílias. Tampouco será prejudicial às psicólogas, aos assistentes sociais, à pedagoga e ao juiz. Para tanto, será garantido o anonimato em todas as fases da pesquisa. Os dados, 
quando divulgados pela comunicação científica, não permitirão a identificação pessoal dos casos.

A devolução dos dados será feita mediante a divulgação dos resultados na forma de artigos publicados em revistas científicas e/ou congressos acadêmicos. Não se esperam benefícios diretos com esta pesquisa para os sujeitos envolvidos, mas a avaliação da interlocução entre o Direito e a Psicologia na Seção Psicossocial da Vara de Execuções Penais do Tribunal de Justiça do Distrito Federal e Territórios.

\section{Resultados}

Passar pelos pesados portões de um manicômio judiciário muitas vezes pode ser um caminho sem volta. Entre muros e omissões, milhares de vidas seguem invisíveis aos olhos do Estado e da sociedade. Abandonadas e anônimas, as pessoas consideradas inimputáveis e/ou semi-imputáveis são duplamente marginalizadas, seja pelo estigma do transtorno mental seja pela situação de delinquência.

Essa população tem seus direitos humanos fortemente violados. Um exemplo de tal realidade pode ser pontuado no documentário A Casa dos Mortos, lançado em 2009, filmado no Hospital de Custódia e Tratamento da Bahia (HCT), localizado em Salvador, Bahia. O documentário aborda o cruzamento entre o crime e a loucura, interroga o espectador acerca do lugar do louco infrator na prática, na agenda e no discurso da reforma psiquiátrica.

O prazo mínimo que se aplica por um juiz a uma medida de segurança é de um a três anos (art. 97, § 1ํㅡㄹ do CP). Porém não foi previsto pelo Código Penal um prazo máximo de duração. No entanto, como a Constituição Federal determina que no Brasil não haja pena de caráter perpétuo e que o tempo de prisão não excederá 30 anos (art. 75 do CP), é possível afirmar que a medida de segurança não pode ultrapassar 30 anos de duração. O período de enclausuramento persiste até que se comprove por laudo médico a cessação da periculosidade.

A partir desse olhar, espera-se com esta pesquisa avaliar a interlocução entre o Direito, especificamente a atenção aos direitos humanos, e a Psicologia, na Seção Psicossocial da Vara de Execuções Penais do Tribunal de Justiça do Distrito Federal e Territórios para aprimorar políticas públicas destinadas a pessoas que cumprem medida de segurança no contexto judiciário.

O projeto encontra-se em fase inicial. Dele fazem parte atualmente sete estudantes de graduação da Universidade de Brasília, Andressa da Silva Palmeira (Fisioterapia) Isadora Gonçalves Bonifácio (Saúde Coletiva), Lays Reis Ribeiro (Terapia Ocupacional), Mônica Oliveira da Cruz (Saúde Coletiva), Rayssa de Paula Dantas Trajano (Terapia Ocupacional), 
Rian Pessoa Vieira (Enfermagem) e Sthefânya Shabryny Cavalcante Regis Moreira (Enfermagem).

Foi realizada uma revisão da literatura sobre o tema. Em Manicômios, Prisões e Conventos, de Erving Goffman, foram discutidas as concepções de "instituição total", de "carreira moral" e de "mortificação do eu" dentro da instituição que segue um modelo médico, hospitalar e psiquiátrico. Em O que é loucura, de João Frayse-Pereira, foi debatida a ideia da loucura como parte integrante da própria razão. A determinação dos estados "normal" e "patológico" depende menos da ciência que da cultura e da sociedade. Já em Manicômio mental - a outra face da clausura, de Peter Pal Pelbart, foi analisado o estigma associado ao louco, marca infamante criada não somente pelo manicômio judiciário, como também pelas diversas sociedades e indivíduos que edificam barreiras mentais entre a loucura e o império ditador da razão. A análise e a discussão desse referencial teórico foram de suma importância para os primeiros passos da pesquisa de campo.

Outro material teórico analisado levanta a hipótese de que a medida de segurança tem sido sinônimo de prisão perpétua. Como apontado pelos dados levantados pelo Censo 2011 sobre A custódia e o tratamento psiquiátrico no Brasil, estudo idealizado e coordenado pela professora Debora Diniz, do Departamento de Serviço Social da Universidade de Brasília, há, além da vulnerabilidade dessa população, um cenário alarmante: um em cada quatro indivíduos não deveria estar internado; 47\% estão encarcerados sem fundamentação legal e psiquiátrica; $21 \%$ cumprem pena além da estipulada em sentença; sem contar o contingente internado há mais de 30 anos, contrariando a pena máxima admitida pelo regime jurídico brasileiro, como no famoso caso Índio Febrônio do Brasil, que ficou 57 anos num hospital de custódia no Rio de Janeiro. Entrou com 27 e morreu com 84 anos, dentro do hospital, cumprindo medida de segurança.

Com os resultados do presente trabalho espera-se, assim, averiguar dados que ratifiquem ou retifiquem tal hipótese, além de realizar um novo levantamento desses dados no Distrito Federal com a finalidade de atualização do censo. Ademais e finalmente, mediante a realização de uma pesquisa qualitativa com os profissionais da Seção Psicossocial da Vara de Execuções Penais do Tribunal de Justiça do Distrito Federal e Territórios, visa-se aprofundar e alargar todo o arcabouço analisado.

\section{Referências}

BRANDI, Caroline Quinaglia A. C. S. A fala dos inimputáveis: uma investigação clínica sobre verbos pathicos no contexto da medida de segurança. Dissertação de Mestrado em Psicologia apresentada ao Programa de Pós-Graduação em Psicologia Clínica e Cultura da Universidade de Brasília. Brasília, 2012.

DINIZ, Debora. A casa dos mortos. Filme, 2009. 
DINIZ, Debora. A custódia e o tratamento psiquiátrico no Brasil: censo 2011. Brasília: Letras Livres; Editora Universidade de Brasília, 2013.

FOUCAULT, Michel. História da loucura. São Paulo: Perspectiva, 2008.

GOFFMAN, Erving. Manicômios, prisões e conventos. São Paulo: Perspectiva, 1999.

QUINAGLIA SILVA, Érica e OLIVEIRA, Rosana Medeiros de. Interview with Debora Diniz about the film The House of the Dead. In: Vibrant: Virtual Brazilian Anthropology, 9(2): 534550, Brasília, 2012.

WISEMAN, Frederick. Titicut Follies. Filme, 1967. 